\title{
Impact on Prognosis of Lymph Node Micrometastasis and Isolated Tumor Cells in Stage II Colorectal Cancer
}

\author{
Tai Young Oh, Sun Mi Moon, Ui Sup Shin, Hyang Ran Lee, Sun Hoo Park ${ }^{1}$ \\ Departments of Surgery and ${ }^{1}$ Pathology, Korea Cancer Center Hospital, Seoul, Korea
}

Purpose: Even though the importance of micrometastases (MMS) and isolated tumor cells (ITC) has been brought up by many physicians, its impact on the prognosis in stage II colorectal cancer is uncertain. In this research, we tried to investigate the clinical features of MMS and ITC and to prove any correlation with prognosis.

Methods: The research pool was 124 colorectal cancer patients who underwent a curative resection from April 2005 to November 2009. A total of 2,379 lymph nodes (LNs) were examined, and all retrieved LNs were evaluated by immunohistochemical staining with anti-cytokeratin antibody panel. Clinicopathologic parameters and survival rates were compared based on the presence of MMS or ITC and on the micrometastatic lymph node ratio (mmLNR), which is defined as the number of micrometastatic LNs divided by the number of retrieved LNs.

Results: Out of 124 patients (26.6\%) 33 were found to have MMS or ITC. There were no significant differences in clinicopathologic features, such as gender, tumor location and size, depth of invasion, histologic grade, except for age $(\mathrm{P}=0.04)$. The three-year disease-free survival rate for the MMS or ITC positive group was $85.7 \%$, and that for MMS and ITC negative group was $92.8 \%(\mathrm{P}=0.209)$. The three-year disease-free survival rate for the mmLNR $>0.25$ group was $73.3 \%$, and that for the mmLNR $\leq 0.25$ group was $92.9 \%(\mathrm{P}=0.03)$.

Conclusion: The presence of MMS or ITC was not closely correlated to the prognosis. However, mmLNR is thought to be a valuable marker of prognosis in cases of stage II colorectal cancer.

Keywords: Micrometastases, Isolated tumor cells, Lymph node, Ratio, Colorectal neoplasm

\section{INTRODUCTION}

In Korea, not only is the incidence of colorectal cancer second highest among gastrointestinal malignant tumors, colorectal cancer is also an important disease that is on the increase every year [1]. As interest in the treatment of and the prognosis for colorectal cancer is on the rise, efforts to obtain a prognosis for colorectal cancer have been made continuously, and among them, TNM staging has been generally used as a prognosis predictor. In patients without distant metastasis, infiltration level of the gut wall, pathologic differentia-

Received: November 24, 2010 Accepted: March 27, 2011

Correspondence to: Sun Mi Moon, M.D.

Department of Surgery, Korea Cancer Center Hospital, Gongneung 2-dong,

Nowon-gu, Seoul 139-706, Korea

Tel: +82-2-970-1237, Fax: +82-2-970-2419

E-mail:msm386@yahoo.co.kr

(C) 2011 The Korean Society of Coloproctology

This is an open-access article distributed under the terms of the Creative Commons Attribution NonCommercial License (http://creativecommons.org/licenses/by-nc/3.0) which permits unrestricted noncommercial use, distribution, and reproduction in any medium, provided the original work is properly cited. tion grade, serum level of carcinoembrionic antigen (CEA), tumor deposits, circumferential resection margin, perineural infiltration, lymphatic or vascular invasion, DNA ploidy, expression level of proliferating cell nuclear antigen (PCNA), K-ras mutation, 18q loss of heterozygosity $(\mathrm{LOH})$ analysis, tumor regression grade, microsatellite instability (MSI), etc. have been suggested to be factors associated with prognosis [2-4]. Among them, one of the most important prognostic factors is lymph node metastasis. Together with the infiltration level of the gut wall, the status of lymph node metastasis is applied to determine Duke's staging and TNM staging, and it also provides important information to clinicians for establishing the treatment plan, such as adjuvant chemotherapy [5].

Lymph node metastasis is an important prognostic factor for recurrence. Nonetheless, Adell et al. [6], Broll et al. [7], and Chen and Bilchik [8] reported that in $20-30 \%$ of patients without lymph node metastasis, the disease recurred within 5 years after a radical resection, and as one of prognostic factors for such recurrence, lymph node micrometastasis was mentioned. Generally, for the detection of lymph node metastasis, hematoxylin-eosin (H\&E) staining has been used. It has been reported to be limited to detect- 
ing lymph node micrometastases such as isolated tumor cells. Because of lymph node micrometastasis that was not detected by $\mathrm{H} \&$ E staining, cancer staging was underestimated, and the patient was not treated properly, which may have been associated with recurrence or distant metastasis [7-10]. To overcome such limitations and to detect lymph node metastasis, several methods have been investigated. The representative methods are immunohistochemistry, staining using antibody to antigens expressed in tumor cells, and the reverse transcription polymerase chain reaction (RT-PCR), which applies molecular biological techniques. Nevertheless, until now, whether lymph node micrometastasis detected by such methods is associated with the prognosis for colorectal cancer is still controversial $[7,8]$.

In this study, in colorectal cancer patients in whom lymph node metastasis was not detected by conventional H\&E staining, the effect of micrometastasis and isolated tumor cells on the prognosis for the patients was addressed by examining the rate of detection of micrometastasis and isolated tumor cells with immunohistochemical staining methods using an anti-cytokeratin antibody panel and by analyzing the clinical features of the subject patients.

\section{METHODS}

\section{Study subjects}

Selected from patients who underwent a radical resection for an adenocarcinoma that had developed in the large intestine and the rectum from April 2005 to November 2008, the patients in this study were those in whom lymph node metastasis had not been detected by using histopathological tests and in whom the primary tumors had passed through the intestinal proper muscle layer. Based on the medical records of the subject patients, the gender of the patients, their age, other associated diseases, the presence or absence of bowel obstruction and perforation at the time of surgery, the location, size, Borrmann type, infiltration level, differentiation grade, lymphovascular invasion of the tumor, the number of resected lymph nodes, as clinical variables and pathological characteristics were examined. For the clinical analysis, patients who had undergone surgery for other cancers previously, patients suspected of having hereditary colorectal cancer, and patients treated with chemo-radiation therapy prior to surgery were excluded.

After radical resection, at 3- to 6-month intervals, follow-ups were performed by checking the CEA level, chest and abdominopelvic computed tomography, and colonoscopy. Patients whose followups were not clear, recurrence, death, and the time of death were assessed by individual telephone interviews. The median followup period was 36 months (range, 1 to 62 months).

\section{Pathological methods}

During the study period, the number of sequentially registered subject patients was 124 . A total of 2,379 lymph nodes were resected, and an average of 19 lymph nodes per patient was examined. An additional section, $4 \mu \mathrm{m}$ in thickness, was taken once from all resected lymph nodes, and using Lab Vision Autostainer 480S (Thermo, Astmoor Runcorn, UK), immunohistochemical staining was performed with the primary antibody anti-cytokeratin cocktail (AE1/AE3; Biogenex, San Ramon, CA, USA).

Lymph node micrometastasis was separately defined according to the size of tumor cells in the lymph nodes after immunohistochemical staining as isolated tumor cells (ITC) when the size was less than $0.2 \mathrm{~mm}$ and as micrometastasis (MMS) when the size was between $0.2 \mathrm{~mm}$ and less than $2 \mathrm{~mm}$ (Figs. 1,2) [11]. The micrometastasis lymph node ratio ( $\mathrm{mmLNR}$ ) was calculated by dividing the number of lymph nodes in which lymph node micrometastasis was detected by the total number of resected lymph nodes.

\section{Statistics}

The association of lymph node micrometastasis with other prognostic factors, as well as with the effect of lymph node microme-
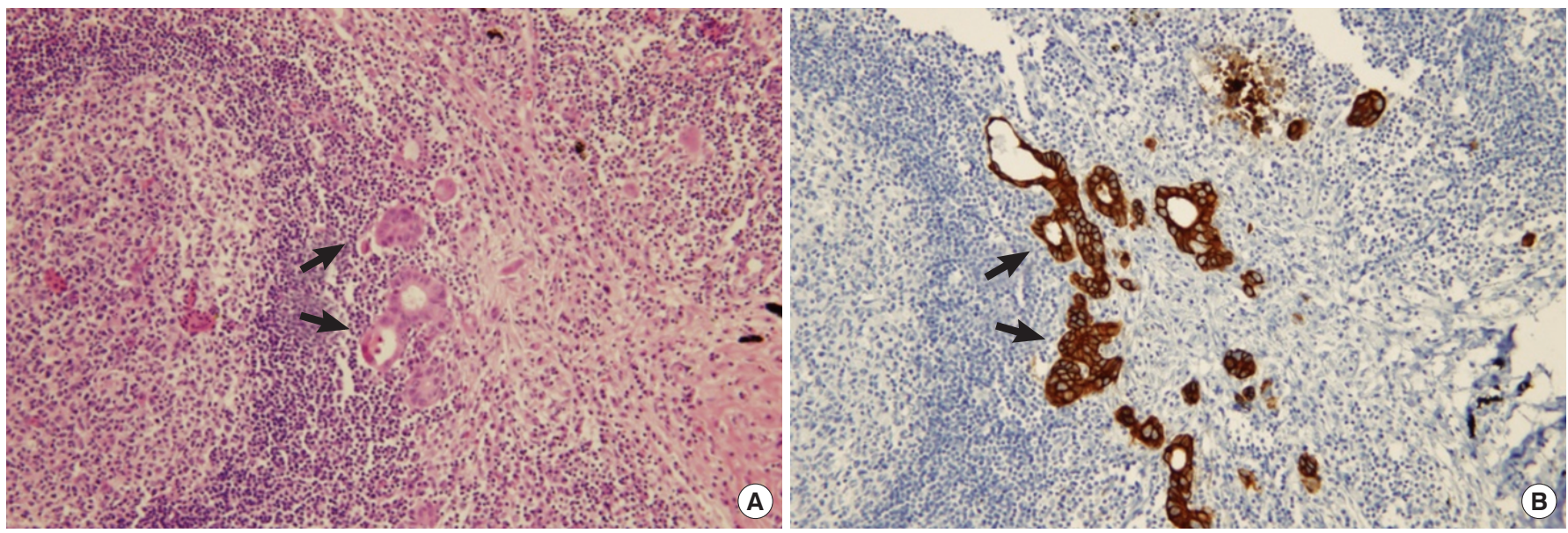

Fig. 1. (A) Foci of nodal micrometastases detected with haematoxylin-eosin (H\&E, $\times 200)$. (B) Foci of nodal micrometastases detected with immunohistochemistry for cytokeratin $($ IHC, $\times 200)$. 


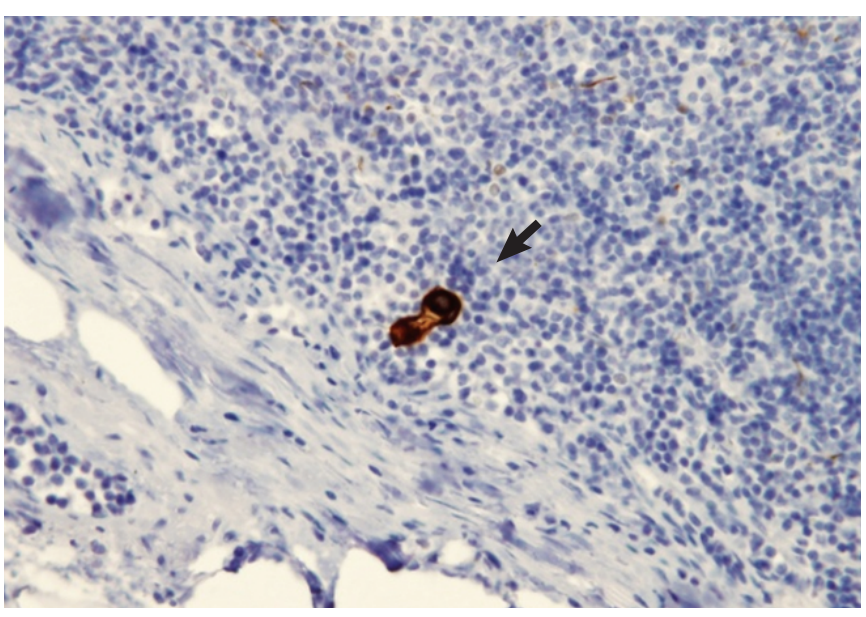

Fig. 2. Foci of isolated tumor cells detected with immunohistochemical staining $(\mathrm{IHC}, \times 400)$.

tastasis on recurrence and death, were analyzed. SPSS ver. 14.0 (SPSS Inc, Chicago, IL, USA) was used. For the analysis of categorical variables, Fisher's exact test or the chi-square test was used. For the analysis of continuous variables, depending on the normality of the variables, the independent variable t-test or the MannWhitney $\mathrm{U}$ test was used. For the analysis of the mortality rate, the Kaplan-Meier test was used, and the mortality rate was analyzed by using the log rank method. For the multivariate regression analysis, the Cox proportional hazard model was used. Variables, including age and gender, whose significant levels were lower than 0.05 in the univariate analysis, were included in the analysis of the variables. In all analyses, a significance level lower than 0.05 was determined to be statistically significant.

\section{RESULTS}

\section{Clinical features of lymph node micrometastasis}

The study subjects were 124 patients, their mean age was 61.2 years $( \pm 11.6)$, and the ratio of males and females was 81:43. From the subject patients, a total of 2,379 lymph nodes were resected, and lymph node micrometastasis was detected in 148 of those lymph nodes (6.3\%). Of the 124 patients, micrometastasis was detected in 33 patients (26.6\%) (Table 1). Among the detected lymph node metastases, micrometastasis larger than $0.2 \mathrm{~mm}$ but smaller than $2 \mathrm{~mm}$ was detected in 2 of the 124 patients (1.6\%), and the number of lymph nodes with micrometastasis was $2(0.08 \%)$. Isolated tumor cells that were smaller than $0.2 \mathrm{~mm}$ were detected in $31 \mathrm{pa}-$ tients (25\%) and the number of lymph node with isolated tumor cells was 146 (6.14\%). In none of the patients were micrometastasis and isolated tumor cells detected simultaneously. In the median value per patient 4 lymph nodes (range, 1 to 14 ), micro lymph node metastasis was detected, and the median value of the lymph node micrometastasis rate was 0.2 (range, 0.02 to 0.63 ). Among the 124 subject patients, 109 patients had lymph node micrometastasis
Table 1. Clinicopathologic characteristics according to presence of micrometastases or isolated tumor cells

\begin{tabular}{|c|c|c|c|c|}
\hline Variable & Patients & $\begin{array}{l}\text { MMS and ITC } \\
\text { negative }\end{array}$ & $\begin{array}{l}\text { MMS or ITC } \\
\text { positive }\end{array}$ & P-value \\
\hline Total & 124 & $91(73.4)$ & 33 (26.6) & \\
\hline Gender & & & & 0.506 \\
\hline Male & 81 & $61(67.0)$ & $20(60.6)$ & \\
\hline Female & 43 & $30(33.0)$ & $13(39.4)$ & \\
\hline Age (yr) & $61.2 \pm 11.6$ & 0.04 & & \\
\hline ASA score & & & & 0.641 \\
\hline$<3$ & 94 & 70 (76.9) & 24 (72.7) & \\
\hline$\geqq 3$ & 30 & $21(23.1)$ & $9(27.3)$ & \\
\hline Location & & & & 0.84 \\
\hline Colon & 61 & $44(48.4)$ & 17 (51.5) & \\
\hline Rectum & 63 & 47 (51.6) & $16(48.5)$ & \\
\hline Borrmann type & & & & 0.644 \\
\hline I, || & 93 & 67 (73.6) & $26(78.8)$ & \\
\hline III, IV & 31 & 24 (26.4) & $7(21.2)$ & \\
\hline Obstruction & 8 & $6(6.6)$ & $2(6.1)$ & 1 \\
\hline Perforation & 2 & $1(1.1)$ & $1(3.0)$ & 0.463 \\
\hline Histologic grade & & & & 1 \\
\hline $\mathrm{G} 1,2$ & 120 & $88(96.7)$ & $32(97.0)$ & \\
\hline $\mathrm{G} 3,4$ & 4 & $3(3.3)$ & $1(3.0)$ & \\
\hline Tumor size (cm) & $5.7 \pm 2.1$ & 0.845 & & \\
\hline Depth of invasion & & & 0.083 & \\
\hline T3 & 116 & 87 (96.7) & 29 (87.9) & \\
\hline $\mathrm{T} 4$ & 7 & $3(3.3)$ & $4(12.1)$ & \\
\hline Retrieved LN & $19.2 \pm 9.8$ & 0.29 & & \\
\hline LVN invasion & 48 & 31 (34.1) & 17 (51.5) & 0.096 \\
\hline Chemotherapy & & & & 0.383 \\
\hline None & 17 & $11(12.1)$ & $6(18.2)$ & \\
\hline $\mathrm{FL}$ & 105 & 79 (86.8) & 26 (78.9) & \\
\hline FOLFOX & 2 & $1(1.1)$ & $1(2.9)$ & \\
\hline
\end{tabular}

Values are presented as number (\%) or mean \pm SD.

MMS, micrometastasis; ITC, isolated tumor cells; ASA, American Society of Anesthesiologists; G1, well differentiated; G2, moderately differentiated; G3, poorly differentiated; G4, undifferentiated or signet ring cell; LN, lymph node; LVN, lymphovascular nerve; FL, fluorouracil + leucovorin; FOLFOX, folinic acid (leucovorin) + fluorouracil + oxaliplatin.

rates lower than 0.25 , and 15 patients had rates higher than 0.25 (Table 2).

During the follow-up observation period, recurrence was confirmed in 12 patients, and 7 patients expired. In regard to recurrence sites, liver metastasis were seen in 9 cases $(75 \%)$, which was the most prevalent, pulmonary metastasis in 1 case and local recurrence in 2 cases (Table 3). Among the 7 patients who succumbed 
to the disease, the cause of death in 5 cases was death pertinent to colorectal cancer, the cause of death in another case was primary lung cancer detected during the follow-up observation, and the cause of death in the last case was postsurgical sepsis.

\section{Association of lymph node micrometastasis with other prognostic factors}

The patient group in which lymph node micrometastasis had been detected and the patient group in which no lymph node micrometastasis had been detected were compared. It was observed that the mean age of the patient group with lymph node micrometastasis was 64.9 years $( \pm 10.2)$, which was higher than the 59.8 years $( \pm 11.6)$ for the group without lymph node micrometastasis $(\mathrm{P}=$ 0.04). Nonetheless, other than that, gender, the location and the size of the tumors, the invasion level to the gut wall, the Borrmann type, the pathologic differentiation grade, the number of resected lymph nodes, the presence of absence of lymphatic or vascular invasion, the presence or absence of bowel obstruction or bowel perforation, and the ASA grade of the two groups showed no statistically significant differences (Table 1).

\section{Lymph node micrometastasis and recurrence}

When the 3-year disease-free survival of the patient group without lymph node micrometastasis was compared with that of the patient group with lymph node micrometastasis, it was $92.8 \%$ and

Table 2. Patient number according to micrometastasis lymph node ratio

\begin{tabular}{lcc}
\hline & $m m L N R \leqq 0.25$ & $m m L N R>0.25$ \\
\hline Total & 109 & 15 \\
MMS or ITC positive & 18 & 15 \\
Mean mmLNR & $0.02 \pm 0.06$ & $0.42 \pm 0.19$ \\
\hline
\end{tabular}

MMS, micrometastasis; ITC, isolated tumor cells; mmLNR, micrometastasis lymph node ratio.

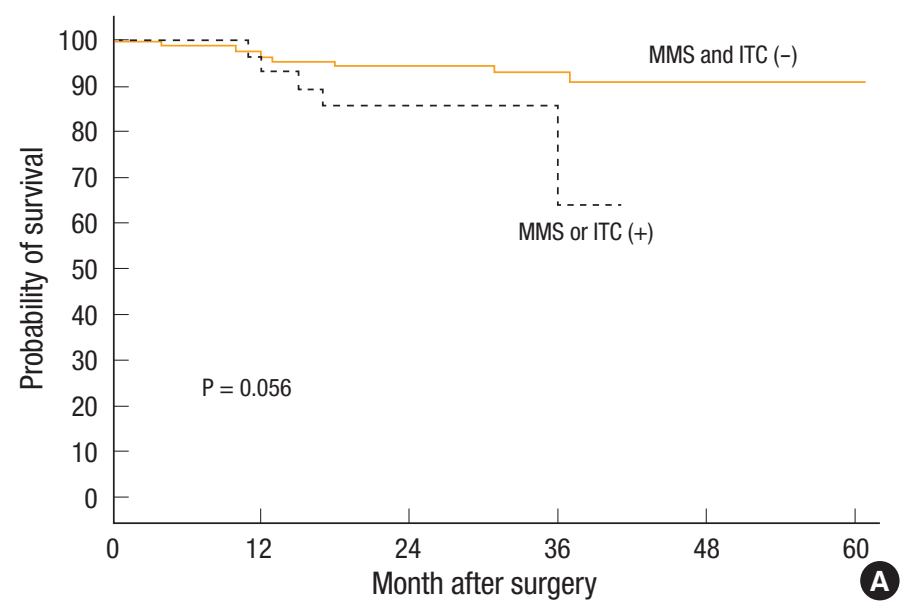

$64.2 \%$, respectively, and a tendency for the disease-free survival rate of the group with lymph node micrometastasis to be low was shown; nonetheless, the difference was not statistically significant $(P=0.056)$ (Fig. 3). When the disease-free survival rate was compared based on the mmLNR, in the cases with mmLNR $>0.25$, the 3-year disease-free survival rate was $73.3 \%$, which was significantly lower than the $92.9 \%$ for the cases with $\operatorname{mmLNR} \leqq 0.25$ (P $=0.03)$ (Fig. 4).

When the effects on recurrence were analyzed by using a univariate regression analysis, Borrmann type higher than III (hazard ratio $[\mathrm{HR}$ ], 3.19; 95\% confidence interval [CI], 1.03 to $9.9 ; \mathrm{P}=$ $0.044)$ and $\mathrm{mmLNR}>0.25$ (HR, 3.91; $95 \% \mathrm{CI}, 1.03$ to $14.82 ; \mathrm{P}=$ 0.045 ) were found to be significant risk factors for recurrence, and no other variables were found to be significant (Table 4). In the multivariate analysis, similarly, Borrmann type higher than III (HR, 4.46; 95\% CI, 1.32 to $15.16 ; \mathrm{P}=0.02$ ) and $\mathrm{mmLNR}>0.25$ (HR, $4.74 ; 95 \% \mathrm{CI}, 1.22$ to $18.47 ; \mathrm{P}=0.03$ ) were found to be independent prognostic factors for recurrence (Table 4).

\section{Lymph node micrometastasis and survival rate}

The overall 3-year survival rate pertinent to colorectal cancer of the group with lymph node micrometastasis was $96.3 \%$, but it was not significantly different from the $97.6 \%$ for the group without lymph node micrometastasis $(\mathrm{P}=0.75)$ (Fig. 3). When the 124 sub-

Table 3. Patient numbers for distant metastasis and local recurrence

\begin{tabular}{lcc}
\hline & MMS or ITC negative & MMS and ITC positive \\
\hline Total & 7 & 5 \\
Distant metastasis & & \\
Liver & 6 & 3 \\
Lung & 1 & 0 \\
Local recurrence & 0 & 2 \\
\hline
\end{tabular}

MMS, micrometastasis; ITC, isolated tumor cells.

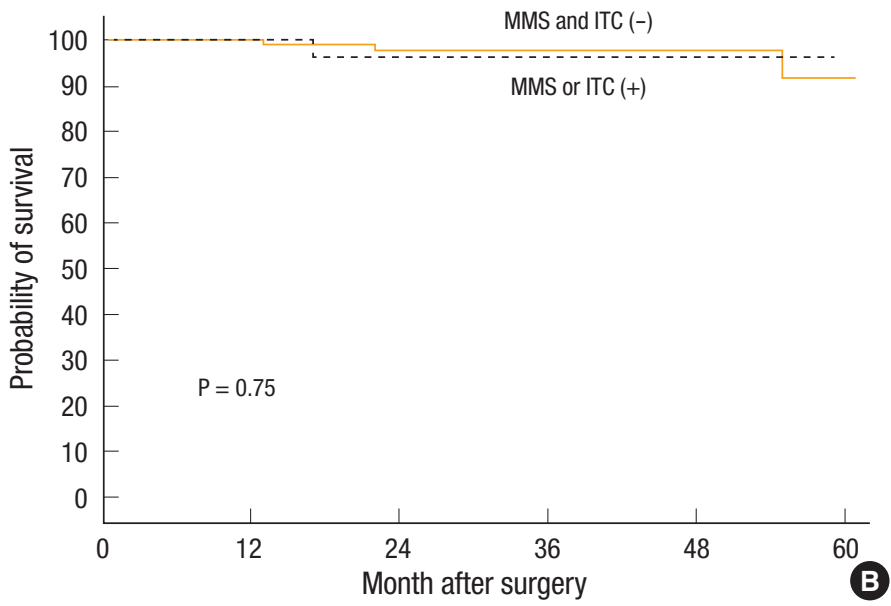

Fig. 3. Survival according to presence of micrometastases or isolated tumor cells: (A) disease-free survival and (B) overall survival. MMS, micrometastasis; ITC, isolated tumor cells. 
ject patients were analyzed based on a micrometastasis lymph node ratio of 0.25 , the overall 3-year survival rate was $90.9 \%$ in the cases with mmLNR $>0.25$, a relatively low survival rate in comparison with the $98.0 \%$ for the cases with $\mathrm{mmLNR} \leqq 0.25$, but this result was not statistically significant $(\mathrm{P}=0.15)$ (Fig. 4).

\section{DISCUSSION}

In colorectal cancer, lymph node metastasis is not only an important prognostic factor but also an important criterion to determine whether or not to administer postsurgical adjuvant therapies and to choose adjuvant therapies. With the development of medical techniques, histopathological equipment and methods, small-sized tumor cells that could not be detected by conventional H\&E staining could be detected, and such cells were termed as micrometastasis and began to be investigated. The term micrometastasis was used in breast cancer for the first time and referred to lymph node lesions smaller than $2 \mathrm{~mm}$. In breast cancer, the usefulness of micrometastasis has been proven, so it has been used widely for the classification of TNM disease stage $[2,12]$. Nonetheless, in colorec-
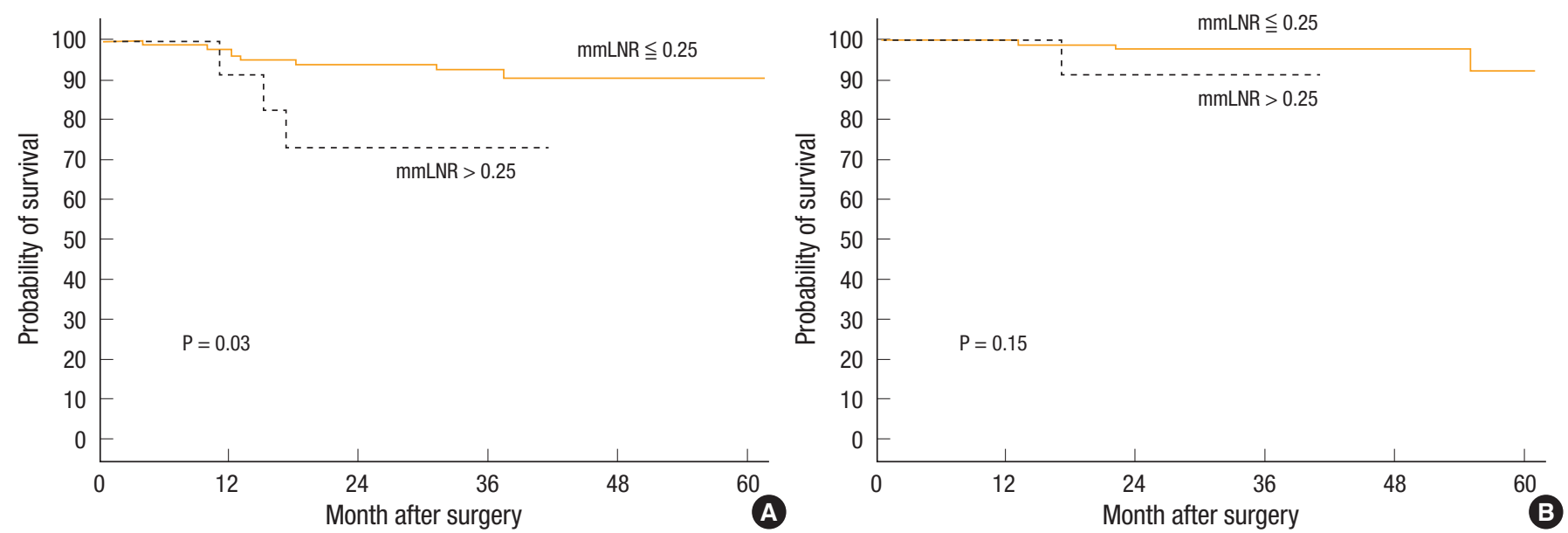

Fig. 4. Survival according to micrometastasis lymph node ratio (mmLNR): (A) disease-free survival and (B) overall survival.

Table 4. Factors associated with recurrence in stage II colorectal cancer (uni- and multi-variate analysis)

\begin{tabular}{|c|c|c|c|c|c|c|}
\hline & \multicolumn{3}{|c|}{ Univariate analysis } & \multicolumn{3}{|c|}{ Multivariate analysis } \\
\hline & $\mathrm{HR}$ & $95 \% \mathrm{Cl}$ & P-value & $\mathrm{HR}$ & $95 \% \mathrm{Cl}$ & P-value \\
\hline Gender (Female) & 0.74 & $0.19-2.8$ & 0.661 & 0.82 & $0.21-3.16$ & 0.78 \\
\hline Age $>60 y r$ & 1.67 & $0.5-5.54$ & 0.405 & 1.31 & $0.38-4.58$ & 0.67 \\
\hline$A S A \geqq 3$ & 1.57 & $0.47-5.23$ & 0.459 & & & \\
\hline Location (Rectum) & 1.31 & $0.42-4.14$ & 0.642 & & & \\
\hline Borrmann type III, IV & 3.19 & $1.03-9.9$ & 0.044 & 4.46 & $1.32-15.16$ & 0.02 \\
\hline Histologic grade $\geqq \mathrm{G}^{\mathrm{a}}$ & 0.047 & $0.0-108.2$ & 0.675 & & & \\
\hline Obstruction (+) & 1.61 & $0.21-12.45$ & 0.65 & & & \\
\hline Perforation (+) & 5.54 & $0.71-43.1$ & 0.102 & & & \\
\hline Tumor size $>5 \mathrm{~cm}$ & 3.74 & $0.82-17.07$ & 0.089 & & & \\
\hline Depth of invasion T4 & 1.79 & $0.23-13.87$ & 0.579 & & & \\
\hline Retrieved LNs < 12 & 0.78 & $0.17-3.55$ & 0.745 & & & \\
\hline LVN invasion (+) & 1.14 & $0.36-3.61$ & 0.818 & & & \\
\hline Chemotherapy (+) & 0.73 & $0.09-5.69$ & 0.766 & & & \\
\hline MMS (+) or ITC (+) & 3.01 & $0.92-9.83$ & 0.069 & & & \\
\hline mmLNR > 0.25 & 3.91 & $1.03-14.82$ & 0.045 & 4.74 & $1.22-18.47$ & 0.03 \\
\hline
\end{tabular}

${ }^{\mathrm{a} G 3}$ is poorly differentiated.

$\mathrm{Cl}$, confidence interval; ASA, American Society of Anesthesiologists; G3 is poorly differentiated; LVN, lymphovascular nerve; MMS, micrometastasis; ITC, isolated tumor cells; mmLNR, micrometastasis lymph node ratio. 
tal cancer, the clinical features of micrometastases have not been reported abundantly, and a consensus on the association between micrometastasis and prognosis has not been reached. According to the American Joint Committee on Cancer, in colorectal cancer, similar to breast cancer, lesions $0.2-2.0 \mathrm{~mm}$ in diameter are defined as micrometastases, and lesions smaller than $0.2 \mathrm{~mm}$ are defined as isolated tumor cells [11]. Nevertheless, such a definition according to the size cannot be applied to molecular biology methods such as RT-PCR; thus, it has been proposed that they be referred to as occult tumor cells or occult lymph node metastases. In addition, different results for their correlation to prognosis, depending on the methods, have been observed, so integrated comprehensive studies are required [13-15].

In recent studies, Park et al. [16] reported that no effect on prognosis of micrometastases detected in stage 1 or 2 colorectal cancer by $\mathrm{H} \& \mathrm{E}$ staining and immunohistochemical staining was observed and that only previously known factors, such as lymphatic invasion and the number of resected lymph nodes, were associated with prognosis. Lee et al. [17] reported that isolated tumor cells in stage 1 or 2 colorectal cancer patients detected by immunohistochemical staining did not affect prognosis $(\mathrm{P}=0.981)$. On the other hand, Bosch et al. [18] reported that in 39 stage 2 colorectal cancer patients without lymph node metastasis, micrometastases or isolated tumor cells, which were thought to be occult metastatic lesions of the lymph node, were examined by immunohistochemical staining, and the group in which micrometastasis or isolated tumor cells had been detected was found to show a statistically significantly lower overall survival rate compared to the group in which micrometastases or isolated tumor cells had not been detected $(\mathrm{P}=0.006)$.

On the other hand, Liefers et al. [9], who used RT-PCT as a pathological method, reported that lymph node micrometastasis was detected in $54 \%$ of the examined stage 2 colorectal patients, and when their 5-year survival rates were compared, it was 50\% in the group with lymph node micrometastasis and $91 \%$ in the group without lymph node micrometastasis, a statistically significant difference $(\mathrm{P}=0.02)$. Thus, lymph node micrometastasis may be associated with prognosis. In an interim report of a recently ongoing prospective study conducted on the usefulness of lymph node micrometastasis in colorectal cancer, Bilchik et al. [15] reported that in the patient group in which lymph node micrometastasis was not detected through the use of H\&E staining, immunohistochemical staining, and RT-PCR, recurrence was detected in none of the cases during the follow-up observation period, and in the patient group in which lymph node micrometastasis was detected for more than one technique, recurrences were more abundant. Thus, after a sufficient follow-up observation period, significant results should be shown in the final report.

In pathological test methods, different results are shown according to the frequency of taking additional sections. In the results reported by Lee et al. [17], sectioning was performed once for $\mathrm{H} \& \mathrm{E}$ staining and immunohistochemical staining, and isolated tumor cells had no effect on prognosis. On the other hand, in the result reported by Yasuda et al. [19], sectioning, $3 \mu \mathrm{m}$ in thickness, was performed once for $\mathrm{H} \& \mathrm{E}$ staining and sectioning, $6 \mu \mathrm{m}$ in thickness, was performed 5 times for immunohistochemical staining, and lymph node micrometastasis was statistically significantly associated with prognosis. Verrill et al. [20] reported that in 100 colorectal cancer patients, in addition to conventional lymph node sectioning, additional sectioning at $100 \mu \mathrm{m}$ intervals was performed twice; thus, sectioning was performed three times, stage of $12 \mathrm{pa}$ tients was upstaged. In 3 of those patients, lymph node metastasis was newly detected; thus, the disease stage, pN0, was adjusted to a $\mathrm{pN} 1$ disease stage. In recently reported studies on lymph node micrometastasis, results have been reported for sectioning repeated for from 5 to as many as 10 times. Multiple lymph node sectioning has been reported to not only raise the rate of the detection of lymph node micrometastasis but also to make clearer the association of disease stage with prognosis [19, 21]. In addition, in order to improve the quality of pathological tests, Brown et al. [22] used lymph node fat clearing techniques, and at that time, the number of resected lymph node was increased and the TNM stage $(\mathrm{pN})$ was upstaged in some cases. Therefore, for the detection of occult lymph node metastasis, not only is the precise resection of lymph nodes thought to be required, but also an increase in the number of sectionings may be of help. Nevertheless, for the fact that such procedures require long time, high cost, and more personnel should be kept in mind.

Recently, instead of $\mathrm{N}$ disease stage, which could be readily influenced by the range of lymph node resection during surgery, the experience level of the surgeon and the level of extraction of lymph nodes from specimens, attention has been paid to the lymph node ratio (LNR), which is the ratio of the number of metastatic lymph nodes to the total number of resected lymph nodes because of its association with prognosis and its importance [23-25]. Telian and Bilchik [25] reported significant differences in the recurrence rates and the survival rates based on a lymph node ratio of 0.25 in stage 3 colorectal cancer patients. Wang et al. [26] reported that the prognoses of 24,477 stage 3 colorectal cancer patients who were registered in the Surveillance, Epidemiology, and End Result (SEER) cancer registry were significantly different, depending on lymph node ratio, which they divided into four groups. Nonetheless, the concept of such a ratio has not been applied to studies on lymph node micrometastasis in stage 2 colorectal cancer patients.

In our study, the concept of the mmLNR was applied to lymph node micrometastases that were detected by adding one additional sectioning, and it was observed that lymph node micrometastasis was statistically significantly associated with recurrence in stage 2 colorectal cancer patients. When the cost and the time required to section lymph nodes several times or to perform RT-PCR to detect lymph node micrometastasis are considered, from a practical point of view, it is anticipated that it may become a useful prognostic factor that can be readily applied. Nonetheless, considering the relatively short follow-up observation of our study, longer, prospective, and multicenter studies are thought to be required. 
By analyzing not only the presence and number of lymph node micrometastasis but also the mmLNR for the prediction of the prognosis in stage II colorectal cancer patients, the usefulness and the possibility of a clinical approach using the mmLNR were demonstrated. However, the association of the clinical features of lymph node micrometastasis with prognosis showed diverse results, depending on the pathological methods, the analysis methods, etc.; thus, it is difficult to derive concurrent results. Thus, more studies and comparative analyses are required.

\section{CONFLICT OF INTEREST}

No potential conflict of interest relevant to this article was reported.

\section{REFERENCES}

1. National Cancer Center. Cancer incidence in Korea 1999-2001. Goyang: National Cancer Center; 2005.

2. Edge, Stephen B. AJCC cancer staging manual. 7th ed. New York: Springer; 2010.

3. Chapuis PH, Dent OF, Fisher R, Newland RC, Pheils MT, Smyth E, et al. A multivariate analysis of clinical and pathological variables in prognosis after resection of large bowel cancer. Br J Surg 1985; 72:698-702.

4. Choi HJ, Jung IK, Kim SS, Hong SH. Proliferating cell nuclear antigen expression and its relationship to malignancy potential in invasive colorectal carcinomas. Dis Colon Rectum 1997;40:51-9.

5. NIH consensus conference. Adjuvant therapy for patients with colon and rectal cancer. JAMA 1990;264:1444-50.

6. Adell G, Boeryd B, Franlund B, Sjodahl R, Hakansson L. Occurrence and prognostic importance of micrometastases in regional lymph nodes in Dukes' B colorectal carcinoma: an immunohistochemical study. Eur J Surg 1996;162:637-42.

7. Broll R, Schauer V, Schimmelpenning H, Strik M, Woltmann A, Best $\mathrm{R}$, et al. Prognostic relevance of occult tumor cells in lymph nodes of colorectal carcinomas: an immunohistochemical study. Dis Colon Rectum 1997;40:1465-71.

8. Chen SL, Bilchik AJ. More extensive nodal dissection improves survival for stages I to III of colon cancer: a population-based study. Ann Surg 2006;244:602-10.

9. Liefers GJ, Cleton-Jansen AM, van de Velde CJ, Hermans J, van Krieken JH, Cornelisse CJ, et al. Micrometastases and survival in stage II colorectal cancer. N Engl J Med 1998;339:223-8.

10. Mori M, Mimori K, Inoue H, Barnard GF, Tsuji K, Nanbara S, et al. Detection of cancer micrometastases in lymph nodes by reverse transcriptase-polymerase chain reaction. Cancer Res 1995;55:3417-20.

11. Singletary SE, Greene FL, Sobin LH. Classification of isolated tumor cells: clarification of the 6th edition of the American Joint Committee on Cancer Staging Manual. Cancer 2003;98:2740-1.

12. Huvos AG, Hutter RV, Berg JW. Significance of axillary macrome- tastases and micrometastases in mammary cancer. Ann Surg 1971; 173:44-6.

13. Nicastri DG, Doucette JT, Godfrey TE, Hughes SJ. Is occult lymph node disease in colorectal cancer patients clinically significant? A review of the relevant literature. J Mol Diagn 2007;9:563-71.

14. Noura S, Yamamoto H, Ohnishi T, Masuda N, Matsumoto T, Takayama O, et al. Comparative detection of lymph node micrometastases of stage II colorectal cancer by reverse transcriptase polymerase chain reaction and immunohistochemistry. J Clin Oncol 2002;20:4232-41.

15. Bilchik AJ, Hoon DS, Saha S, Turner RR, Wiese D, DiNome M, et al. Prognostic impact of micrometastases in colon cancer: interim results of a prospective multicenter trial. Ann Surg 2007;246:568-75.

16. Park SJ, Lee KY, Kim SY. Clinical significance of lymph node micrometastasis in stage I and II colon cancer. Cancer Res Treat 2008; 40:75-80.

17. Lee MR, Hong CW, Yoon SN, Lim SB, Park KJ, Lee MJ, et al. Isolated tumor cells in lymph nodes are not a prognostic marker for patients with stage I and stage II colorectal cancer. J Surg Oncol 2006;93:13-8.

18. Bosch Roig CE, Rosello-Sastre E, Alonso Hernandez S, Almenar Cubells D, Grau Cardona E, Camarasa Lillo N, et al. Prognostic value of the detection of lymph node micrometastases in colon cancer. Clin Transl Oncol 2008;10:572-8.

19. Yasuda K, Adachi Y, Shiraishi N, Yamaguchi K, Hirabayashi Y, Kitano S. Pattern of lymph node micrometastasis and prognosis of patients with colorectal cancer. Ann Surg Oncol 2001;8:300-4.

20. Verrill C, Carr NJ, Wilkinson-Smith E, Seel EH. Histopathological assessment of lymph nodes in colorectal carcinoma: does triple levelling detect significantly more metastases? J Clin Pathol 2004;57:1165-7.

21. Sasaki M, Watanabe H, Jass JR, Ajioka Y, Kobayashi M, Matsuda $\mathrm{K}$, et al. Occult lymph node metastases detected by cytokeratin immunohistochemistry predict recurrence in "node-negative" colorectal cancer. J Gastroenterol 1997;32:758-64.

22. Brown HG, Luckasevic TM, Medich DS, Celebrezze JP, Jones SM. Efficacy of manual dissection of lymph nodes in colon cancer resections. Mod Pathol 2004;17:402-6.

23. Vaccaro CA, Im V, Rossi GL, Quintana GO, Benati ML, Perez de Arenaza D, et al. Lymph node ratio as prognosis factor for colon cancer treated by colorectal surgeons. Dis Colon Rectum 2009;52: 1244-50.

24. Noura S, Ohue M, Kano S, Shingai T, Yamada T, Miyashiro I, et al. Impact of metastatic lymph node ratio in node-positive colorectal cancer. World J Gastrointest Surg 2010;2:70-7.

25. Telian SH, Bilchik AJ. Significance of the lymph node ratio in stage III colon cancer. Ann Surg Oncol 2008;15:1557-8.

26. Wang J, Hassett JM, Dayton MT, Kulaylat MN. Lymph node ratio: role in the staging of node-positive colon cancer. Ann Surg Oncol 2008;15:1600-8. 